\title{
Insights into Candida tropicalis nosocomial infections and virulence factors
}

\author{
M. Negri • S. Silva $・$ M. Henriques $\cdot$ R. Oliveira
}

Received: 14 September 2011 / Accepted: 8 October 2011 / Published online: 30 October 2011

(C) Springer-Verlag 2011

\begin{abstract}
Candida tropicalis is considered the first or the second non-Candida albicans Candida (NCAC) species most frequently isolated from candidosis, mainly in patients admitted in intensive care units (ICUs), especially with cancer, requiring prolonged catheterization, or receiving broad-spectrum antibiotics. The proportion of candiduria and candidemia caused by $C$. tropicalis varies widely with geographical area and patient group. Actually, in certain countries, $C$. tropicalis is more prevalent, even compared with $C$. albicans or other NCAC species. Although prophylactic treatments with fluconazole cause a decrease in the frequency of candidosis caused by $C$. tropicalis, it is increasingly showing a moderate level of fluconazole resistance. The propensity of $C$. tropicalis for dissemination and the high mortality associated with its infections might be strongly related to the potential of virulence factors exhibited by this species, such as adhesion to different host surfaces, biofilm formation, infection and dissemination, and enzymes secretion. Therefore, the aim of this review is to outline the present knowledge on all the abovementioned $C$. tropicalis virulence traits.
\end{abstract}

Keywords Candida tropicalis $\cdot$ Epidemiology $\cdot$ Risk factors · Virulence factors · Candiduria $\cdot$ Candidemia

\section{Introduction}

Nosocomial infections (NIs), or in other words hospital acquired infections, are now a serious public health

M. Negri $\cdot$ S. Silva $\cdot$ M. Henriques $(\bowtie) \cdot$ R. Oliveira Institute for Biotechnology and Bioengineering (IBB), Centre of Biological Engineering, Universidade do Minho, Campus de Gualtar,

4710-057 Braga, Portugal

e-mail: mcrh@deb.uminho.pt problem, since these infections are among the leading causes of morbidity and mortality, causing an increase in hospitalization time and, consequently, high costs associated to patient's treatment $[1,2]$. NIs have been particularly prominent in intensive care units (ICUs), where the incidence is two to five times higher than in the general population of hospitalized patients $[3,4]$. The causes for the increased risk of NIs in ICUs have been associated with increased length of stay in ICU, invasive procedures, patients with compromised immune systems, and multiple exposure to antibiotics [5-7]. Beyond the hospital unit and the disease involving the patient, factors related to the infecting organism are of major importance to the progression of hospital acquired infections [8]. Most of the NIs are caused by microorganisms of the normal microbiota that attack the patient in special situations such as under immunosupression. In these patients, considered at risk, invasive fungal infections are often severe, with a rapid progression and difficultly to diagnose and/or treat $[1,7]$.

Fungal nosocomial infections (FNIs) incidence has increased significantly over recent decades. Candida species are the most frequently isolated fungi, corresponding to approximately $80 \%$ of FNIs, being the fourth responsible cause for blood stream infections and responsible for the overwhelming majority of urinary tract infections [7, 9, 10].

Until recently, Candida albicans was the Candida species that received major clinical attention. However, in parallel with the overall increase of fungal infections, it has been observed that infections caused by non-Candida albicans Candida (NCAC) species are emerging [7, 11, 12]. The reasons for this alteration in the pattern of Candida species distribution has not yet been completely understood, but could be attributed to the resistance of the NCAC species to antifungal agents, which are used for relatively long periods during hospitalisation [9, 12-14]. 
Usually, Candida tropicalis is considered the first or the second NCAC species most frequently isolated from bloodstream (candidemia) $[12,13,15,16]$ and from urinary tract (candiduria) $[17,18]$ infections. Additionally, $C$. tropicalis is often found in patients admitted to ICUs, especially in patients with cancer, requiring prolonged catheterization, and/or receiving broad-spectrum antibiotics $[8,12]$. This species appears to display higher potential for dissemination in the neutropenic host than C. albicans and other NCAC species. This propensity for dissemination in some way may explain the reported relatively high mortality associated with $C$. tropicalis $[15,19,20]$.

Several virulence factors seem to be responsible for $C$. tropicalis infections, which present high potential for dissemination and mortality [21]. Adhesion to host surfaces (epithelial cells and medical devices), as well as biofilm formation [22, 23], secretion of enzymes (proteases and phospholipases) and haemolytic activity are considered important factors in C. tropicalis infection [22, 24, 25]. Therefore, this article aims to review and discuss $C$. tropicalis general characteristics, focusing on its microbiology, epidemiology, risk factors and mainly on its virulence factors.

\section{Microbiology}

Candida tropicalis, first known as Oidium tropicale, was differentiated among several Candida species in 1910 by Aldo Castellani. Meanwhile other names have been attributed to this species, such as Monilia tropicalis, Candida vulgaris, Mycotorula dimorpha, Candida paratropicalis and another 58 synonyms. Only in 1923, Berkhout introduced the present name [26, 27]. Candida tropicalis is a diploid ascomycete yeast and an opportunistic human pathogen, which colonizes several anatomically distinct sites, including the skin [28, 29], gastrointestinal [30] and genitourinary tracts [28], and may also be seen in the respiratory tract [29]. It can also be recovered from the environment, particularly from surfaces in medical settings [22, 29, 31]. Moreover, since $1960 C$. tropicalis has been recognized as responsible for serious invasive candidosis [32, 33].

Infections caused by $C$. tropicalis can be acquired endogenously, when the individual is already colonized by the microorganism as part of the normal flora, but under altered conditions yeasts may be translocated and spread through the gastrointestinal tract to different anatomic sites, causing infection $[8,12,15]$. The exogenous infection can occur through contact of the hands of health professionals with patients or through catheters, implantable prostheses, as well as parenteral solutions, which were previously contaminated [15, 22, 34, 35].

The mechanism used by the commensal $C$. tropicalis to become a human pathogen is not yet clear. Moreover, $C$. tropicalis infections involve a broad spectrum of invasive diseases, affecting patients exposed to a wide variety of risk factors $[8,36,37]$. Among the invasive infections caused by $C$. tropicalis, the most common are candiduria and candidemia $[13,15,17,18,38]$.

\section{Identification}

Colonies of C. tropicalis are cream-colored with a slightly mycelial border (Fig. 1a) on the routinely used Sabouraud dextrose agar (SDA) and appear dark blue (Fig. 1b) in CHROMagar ${ }^{\mathrm{TM}}$ Candida (CHROMagar, Paris, France) [26, 39]. Microscopically (Fig. 1c), on corn meal Tween 80 agar at $25^{\circ} \mathrm{C}$ (Dalmau method), C. tropicalis shows blastoconidia singly or in small groups all along graceful, long pseudohyphae and may also produce true hyphae.

In biochemical tests (fermentation and assimilation; Table 1), this yeast differs from the other important Candida species by being able to ferment and to assimilate glucose, sucrose, galactose, trehalose, and maltose, but not lactose or rafkose [26, 40, 41].

Genetically, C. tropicalis is more similar to C. albicans, since it contains the major repeat sequence (MRS)
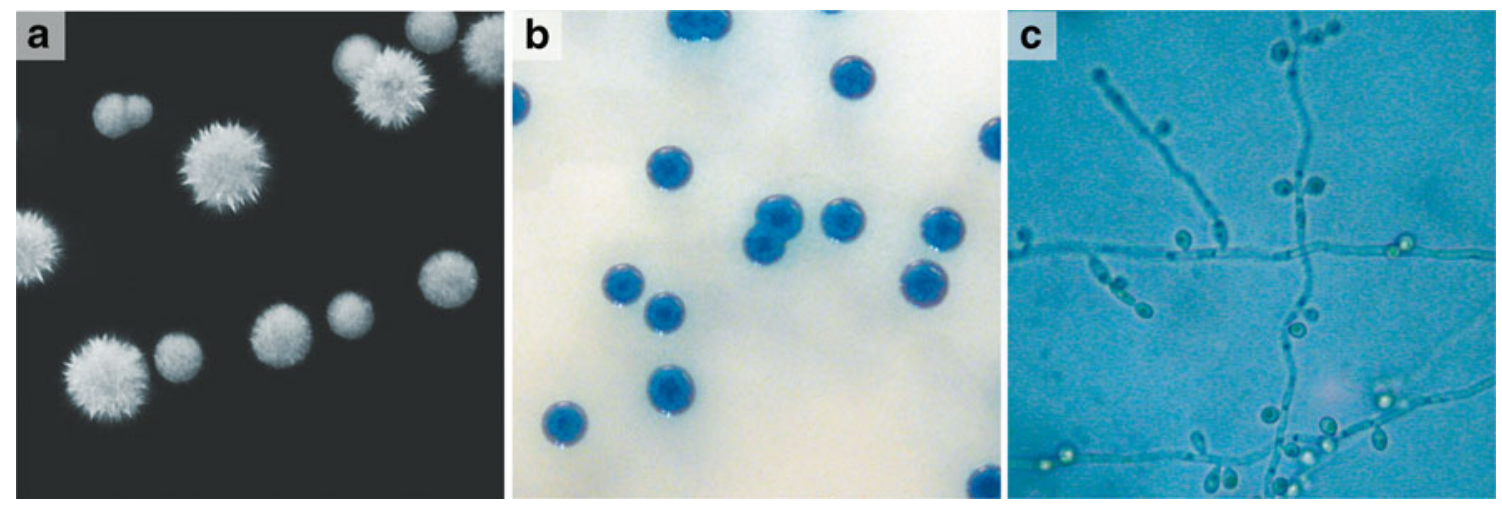

Fig. 1 Candida tropicalis morphology in routine culture media. a Colonies of C. tropicalis on Sabouraud dextrose agar. b On CHROMagar ${ }^{\mathrm{TM}}$ Candida. c On corn meal Tween 80 agar at $25^{\circ} \mathrm{C}$ (Dalmau method) 
Table 1 Microbiological and biochemical characteristics of C. tropicalis compared with other important Candida species

\begin{tabular}{|c|c|c|c|c|c|c|c|c|c|c|c|c|c|c|c|}
\hline \multirow[t]{2}{*}{ Candida specie } & \multicolumn{3}{|c|}{ Microbiology } & \multicolumn{12}{|c|}{ Biochemical $^{\mathrm{a}}$} \\
\hline & Hyphae & Pseudohyphae & Germinative tube & glu & gal & lac & mal & suc & meli & cel & tre & raf & mel & urease & $\mathrm{KHO}_{3}$ \\
\hline C. tropicalis & + & + & - & FA & FA & - & FA & FA & - & $\mathrm{A} \pm$ & FA & - & A & - & - \\
\hline C. albicans & + & + & + & FA & $\mathrm{AF}^{ \pm}$ & - & FA & A & - & - & $\mathrm{AF} \pm$ & - & $\mathrm{A} \pm$ & - & - \\
\hline C. parapsilosis & - & + & - & $\mathrm{AF} \pm$ & A & - & A & $\mathrm{AF} \pm$ & - & - & $\mathrm{AF} \pm$ & - & A & - & - \\
\hline C. glabrata & - & - & - & FA & - & - & - & - & - & - & $\mathrm{A} \pm$ & - & - & - & - \\
\hline
\end{tabular}

${ }^{a}$ Biochemical analyses: Fermentation and assimilation in the presence of a carbon source, such as glucose (glu), galactose (gal), lactose (lac), maltose (mal), sucrose (suc), melibiose (meli), celobiose (cel), trehalose (tre), raffinose (raf), melezitose (mel). Urea hydrolysis (urease) and assimilation of $\mathrm{KHO}_{3}$

+ positive, - negative, $F A$ fermentation and assimilation positive, $A$ assimilation positive, $A \pm$ assimilation variable, $A F \pm$ assimilation positive with fermentation variable

elements, than C. parapsilosis and C. glabrata [42]. The discovery of MRS elements in $C$. tropicalis suggests that these repeats play a similar role in karyotypic variation in this species, although the contribution of these changes to pathogenesis is not known [43, 44].

For molecular identification, several procedures have been proposed to detect and differentiate Candida species in vitro, either by DNA extraction from cultured organisms [45, 46] or directly from clinical samples [47-49]. Methods such as polymerase chain reaction (PCR) assay $[47,49,50]$ and realtime PCR assays [45, 51], described in Table 2, have been successfully used to identify $C$. tropicalis from clinical samples and even when this species is found in the presence of other fungi. Nevertheless, these methodologies are not yet standardized or readily available in most clinical laboratory settings nor have been validated in large clinical trials.

\section{Risk factors}

In general, the risk factors involved in the development of hospital-acquired Candida infections are associated with: extended periods in ICUs, administration of broadspectrum antibiotics, patients with immunosupression, indwelling catheters, mechanical ventilation, candiduria, multiple sites of colonization, burns, and hemodialysis [5, 5254]. However, the particularities of each Candida species may be influenced by specific risk factors. Studies have been shown, that in opposition to $C$. parapsilosis, $C$. tropicalis was less likely to occur among children of less than one year of age, but more likely to occur in patients with cancer or neutropenia $[15,55,56]$, and is strongly associated with the presence of biofilms in urinary catheters. [18, 52, 57-59].

Candida colonization remains the most universally accepted predictive variable with regard to invasive candidiasis, being particularly true for high density colonization. In fact, colonization by $C$. tropicalis, especially from a specific body site can be highly predictive of the development of invasive disease with this organism [60]. Nevertheless, it has not yet been clarified whether colonization can be used alone to identify high-risk patients or if it should be combined with other variables indicating high risk [61]. According to Paul et al. [62], many risk factors traditionally linked to candiduria may be associated with urinary tract infections in general. Furthermore, Binelli et al. [63] found a significant association of candidemia with candiduria, although urine was not the main source of C. tropicalis bloodstream infection.

According to epidemiological data, when comparing patients with candidemia caused by $C$. tropicalis to those caused by other species of Candida, on average, the former are older patients (67 years vs. 56 years, $P=0.01$ ), present cancer $(45.5 \%$ vs. $31.6 \%, P=0.04)$, and the portal of entry is the abdomen $(32.2 \%$ vs. $11.9 \%, P=0.001)$. Additionally, these patients also have a high hospital mortality rate $(61 \%$ vs. $44 \%, P=0.03$ ) [64]. Further studies suggested that $C$. tropicalis is associated with higher dissemination potential and mortality in patients admitted in ICU, particularly in oncology patients, than C. albicans or any other NCAC species $[13,15,65]$.

\section{Epidemiology}

The proportion of candidosis (candidemia and candiduria) caused by $C$. tropicalis varies widely with geographical area and patient group, with $C$. tropicalis being more prevalent, even compared with $C$. albicans, in certain countries [64, 66, 67]. Considering Table 3 , it is possible to see that, among NCAC species, $C$. tropicalis has been considered the species most frequently isolated from candidosis in the Pacific-Asia region [13], Brazil [12, 15], and recently in Europe [7, 68]. Furthermore, important epidemiological studies revealed that $90 \%$ of invasive candidosis were due to NCAC species, with $C$. tropicalis accounting for about $4-6 \%$ in $1997-1998,5.3 \%$ in 1999 , and $7.3 \%$ in 2000-2003 [69]. Additionally, in general, $C$. 
Table 2 Primers and probes used for polymerase chain reaction (PCR) and real-time PCR assay used for the identification of $C$. tropicalis from clinical samples and when this species is found in the presence of other fungi

Molecular method (reference) Sequence (direction)

PCR-based [47]

Multiplex PCR [50, 114]

PCR and pyrosequencing [49]

LightCycler PCR [45, 92]

Real-time PCR assays [48] or funS2:
Description

Primer mixes specific to Candida DNA topoisomerase II genes.

For the identification of Candida tropicalis to the species level, one species-specific forward primer and two species-specific reverse primers were designed within the region amplified by the degenerated primer pair

(F) 5'-CTGGGAAATTATATAAGCAAGTT-3'

(R) 5'-CTTGAGATACTCAATCTTTTATC-3'

(R) 5'-TCAATGTACAATTATGACCGAGTT-3'

ITS1 5'-TCC GTA GGT GAA CCT GCG G-3' ITS2 5'-GCT GCG TTC TTC ATC GAT CG-3'

The method is based on the size variability of the ITS1 region in different species. The fungi-specific primers ITS1 and ITS2 are used to amplify a small conserved portion of the 18S rDNA region, the adjacent ITS1, and a small portion of the $28 \mathrm{~S}$ rDNA region, generating different PCR products for C. glabrata, C. guilliermondii, C. lusitaniae, C. parapsilosis, C. tropicalis and C. krusei

The tests are performed on amplicons derived from the $18 \mathrm{~S}$ rRNA gene using PCR universal primers for amplification. The amplification products were subjected to pyrosequencing analysis - a method $\mathrm{f}$ DNA sequencing (determining the order of nucleotides in DNA) based on the "sequencing by synthesis" principle

funS 5'-YTCAMAGTAAAAGTCCTGG-3' or funS2 5'-TCAAAGTAAAAGTCCTGGTTC-3'

C. tropicalis pyrosequencing with primers funS

TTCGCCAAAAGGCTAGCCAGAAGGAAAG GCTCGGTTGGGTC

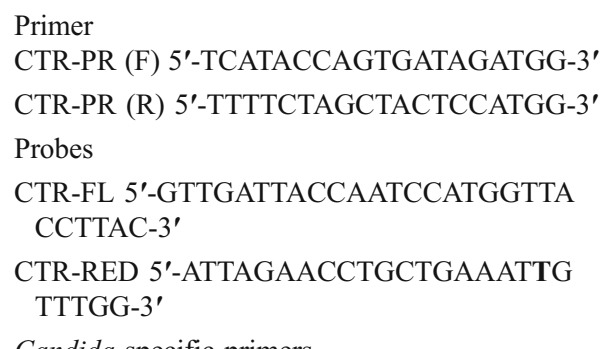

Candida-specific primers

Cand (F) CCTGTTTGAGCGTCRTTT

ITS (R) TCCTCCGCTTATTGATAT

Candida-specific probes

C.trop-S Cy5-GGCCACCACAATTTATTT

CA-biotin
The LightCycler PCR combines rapid amplification of nucleic acids in glass capillary with melting curve analysis based on fluorescence resonance energy transfer for the sensitive detection of point mutations in various settings. Speciesspecific amplification (standard PCR) and hybridization (LightCycler PCR) of Candida DNA could be achieved using the species-specific primer pairs and the oligonucleotides, respectively

The application of the biprobe technology facilitated a rapid screening for fungi (specific for the fungal ITS2 region) and simultaneous differentiation of 11 medically important Aspergillus and Candida species (with species-specific biprobes) in only two individual PCR mixtures and simultaneously in the same LightCycler run

(F) and (R) indicate forward and reverse primers, respectively

tropicalis appeared to be the first or second NCAC most frequently associated to candiduria. Nevertheless, regarding candidemia, $C$. tropicalis is less frequently isolated than $C$. glabrata [7, 17, 52, 65, 68].

Although the reasons for the increased detection of $C$. tropicalis in human infection are not completely clear, the advent of molecular genetics and the development of new methods of Candida identification and differentiation [45,
$47,70]$ may play an important role. Further, the changes of C. tropicalis incidence may also be attributed to the greater use of fluconazole nowadays [64, 67]. In the United States, due to fluconazole prophylaxis the frequency of candidosis caused by $C$. tropicalis has decreased. However, in other countries where it is not usual to use fluconazole prophylaxis, $C$. tropicalis appears more prevalent, e.g. second in Latin America, and even more common than $C$. 
Table 3 Summary of incidence and antifungal resistance attributed to Candida tropicalis candidosis (candidemia and candiduria)

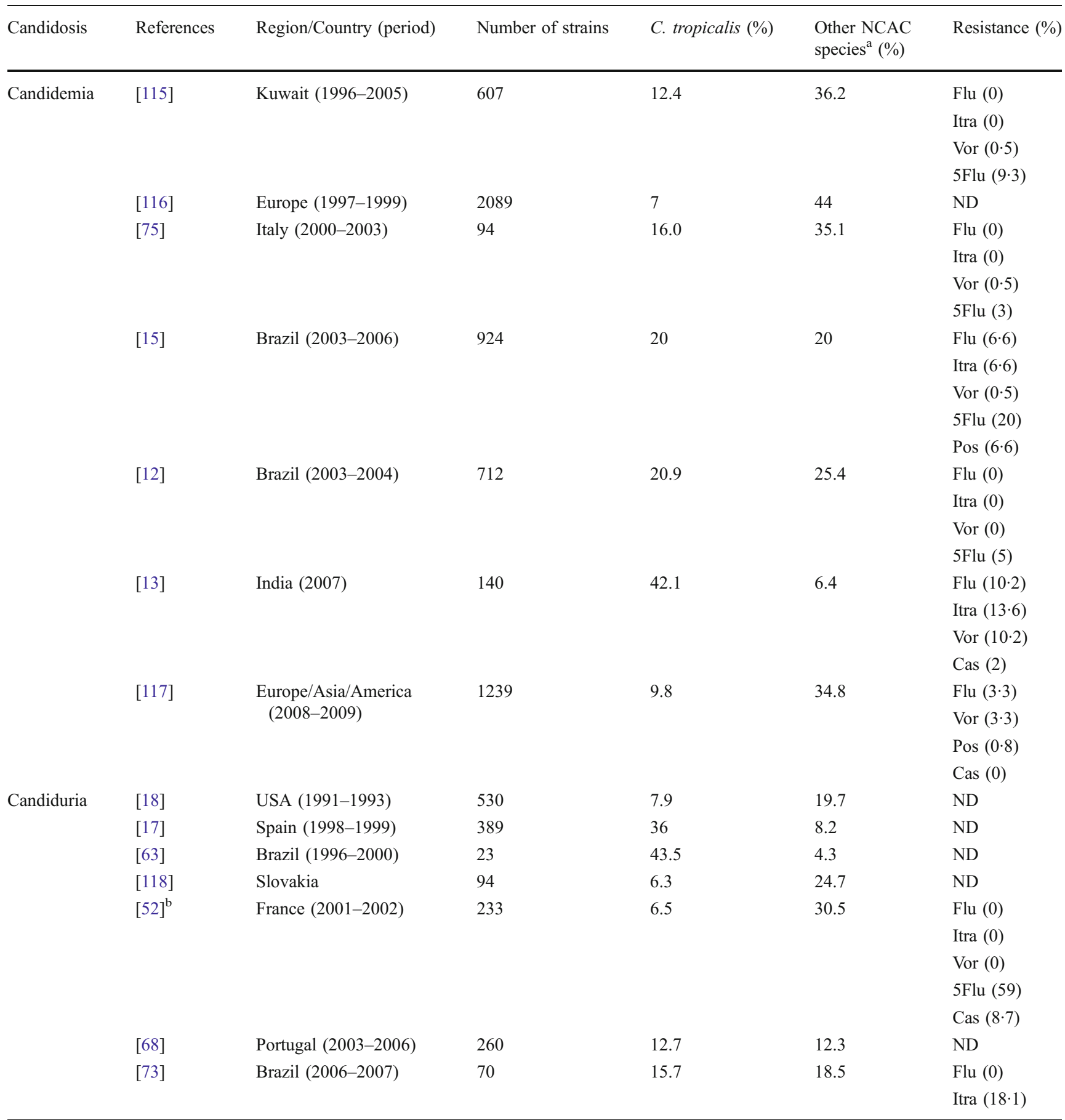

Flu Fluconazole, Itra Itraconazole, Vor Voriconazole, 5Flu 5-Flucytosine, Pos Posoconazole, Cas Caspofungin, ND not determined

${ }^{a}$ Percentage of Candida glabrata and/or Candida parapsilosis

${ }^{\mathrm{b}}$ In vitro susceptibilities of 22 . tropicalis bloodstream and urine isolates

glabrata in the Asia-Pacific region [69]. Nevertheless, the use of prophylactic fluconazole can become a risk factor since some cross-resistance between azoles [7, 11, 71] has been reported already. Several studies indicate that $C$. tropicalis has been showing a moderate level of fluconazole tolerance leading to the need of an increase in the drug concentrations and enabling a risk of azole resistance $[65$, 72, 73].

Curiously, according to Table 3, the epidemiological data related to antifungal resistance have been indicating an 
increase of $C$. tropicalis resistance to 5-flucytosine [12, 15, $52,74,75]$. Furthermore, it was observed $35 \%$ of resistance to 5-flucytosine by $C$. tropicalis isolates recovered from blood cultures in the active surveillance program on yeastrelated fungemia implemented by the French National Reference Center for Mycoses and Antifungals (NRCMA) in the Paris area [74]. Additionally, Densos-Olliver et al. [74] studied the relationship between epidemiologic and genomic data of $C$. tropicalis 5 -flucytosine resistance, and they observed that a clone of 5-flucytosine-resistant isolate, associated with malignancies, had lower mortality than the other $C$. tropicalis isolates. This suggests that geographic and temporal distribution of $C$. topicalis may be related with 5-flucytosine-resistant isolates in the Paris area.

In fact, the major problem with the development of invasive candidosis by $C$. tropicalis is that it is associated with higher mortality than other NCAC species and $C$. albicans $[8,20,66,76]$. This propensity of $C$. tropicalis for dissemination and associated high mortality may be related to the virulence factors exhibited by this species such as biofilm formation, proteinases secretion and dissemination $[11,22]$.

\section{Virulence factors}

Mechanisms used by Candida species with the purpose of causing any type of injury to the host are related to virulence factors. Several mechanisms of pathogenicity have been associated with $C$. tropicalis, such as adhesion to different surfaces (Fig. 2), biofilm formation, capacity of dissemination (Fig. 3), and hyphae and enzymes production. These factors are concisely described in Table 4. Additionally, relevant findings indicate higher pathogenicity for $C$. tropicalis than other NCAC species. Unfortunately, the pathogenic mechanisms of $C$. tropicalis have not been yet fully elucidated $[20,21,64,65,77]$.
Adhesion and biofilm formation

Candida tropicalis possesses a remarkable capacity to adhere to abiotic surfaces, human cells and tissues. It is known that Candida cells have several different adhesins (special cell wall proteins), which allows adhesion to specific substrates. Candida Als (agglutinin-like sequence) is considered an important protein family during the process of adhesion, mediating attachment to different epithelium cells, functioning as an adhesin. Furthermore, southern blot analysis with $A L S$ specific probes suggested the presence of $A L S$ gene families in C. tropicalis [78, 79]. Furthermore, other factors, such as physicochemical interactions between yeast cells and materials surface, as well as environmental factors, can influence the initial adhesion of $C$. tropicalis [21, 80-82]. Several studies showed the ability of C. tropicalis to adhere, and consequently to form biofilms, in clinically relevant substrates like medical devices, and in different environmental situations, both in vitro and in vivo. Adherence of Candida cells to abiotic surfaces and to other cells is vital for biofilm formation [80, 82-85].

Candida biofilm formation is initiated when the yeast adheres to a surface, cells attach to each other and begin to proliferate - ultimately leading to the formation of a highly structured mature biofilm, comprised of complex intertwining layers of yeast, pseudohyphae and hyphae embedded in the extracellular matrix $[86,87]$. The matrix is one of the most distinctive features of a microbial biofilm. This complex extracellular material might function to defend against phagocytic cells, to serve as a scaffold for maintaining biofilm integrity, and to limit diffusion of toxic substances into the biofilm, as antifungals [86, 88]. Further, studies indicate that $C$. tropicalis biofilms exhibit large amounts of matrix material completely resistant to antifungals $[23,65,89-91]$. Those data can explain why the
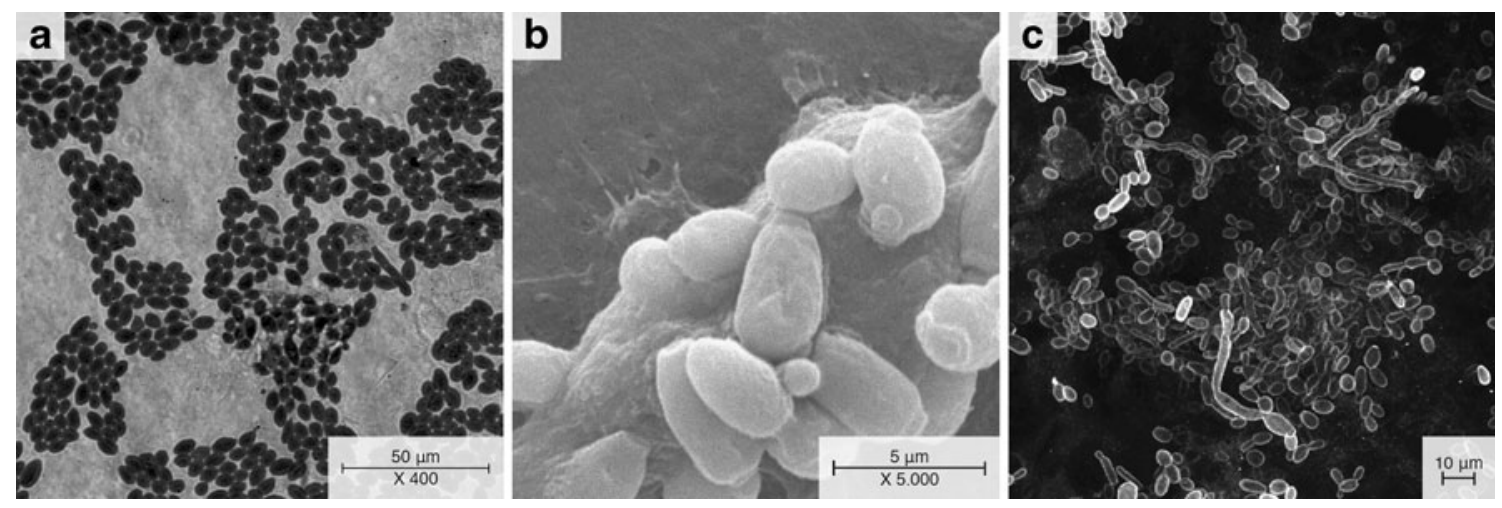

Fig. 2 Candida tropicalis adhered to different surfaces. a Optical micrograph of $C$. tropicalis on silicone coupons. b Scanning electron micrograph of $C$. tropicalis adhered to a human epithelial urinary bladder cell line. c Confocal laser scanning microscopy image of $C$. tropicalis adhered to a reconstituted human oral epithelium 


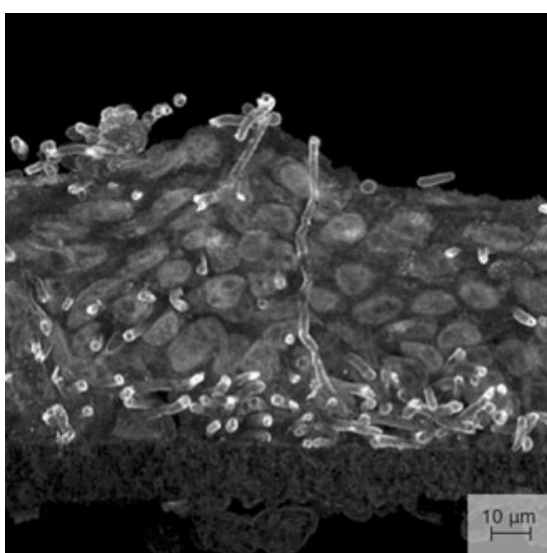

Fig. 3 Confocal laser scanning micrograph of C. tropicalis infecting reconstituted human oral epithelium

major risk factor of $C$. tropicalis in candidose development is related to the difficulty of treatment and, moreover, to the prolonged catheterization $[64,71,92]$.

In a study done by Al-Fattani and Douglas [89], it was shown that the matrix of $C$. tropicalis contained carbohydrates, proteins, hexosamine, phosphorus and uronic acid. The major component in $C$. tropicalis matrix was hexosamine $(27 \%)$, whereas in $C$. albicans matrix it was glucose $(32 \%)$. It is important to emphasize that hexosamine is present in Streptococcus epidermidis as a polysaccharide, which is sometimes referred to as the intercellular polysaccharide adhesin (PIA) and is known to mediate cell-cell interaction within the biofilm [93]. Further, in the same study, biofilms of $C$. albicans were more easily detached from plastic surfaces by treatment with the enzyme lyticase than were those of $C$. tropicalis.

However, C. tropicalis biofilm and consequently matrix composition are extremely dependent on environmental conditions, such as medium composition, $\mathrm{pH}$, oxygen and growth conditions (static or flow) [82, 84, 90]. According to a study by Jain et al. [59] comparing Candida biofilms grown in RPMI medium and artificial urine, biofilm formation is highly dependent on the growth medium. In particular, C. albicans strains produced more biofilm in artificial urine than in RPMI. Furthermore, other researches indicated that biofilms grown under conditions of continuous flow produced more matrix than those grown statically, and were significantly more resistant to amphotericin B [89].

Another important factor about the biofilm life cycle is related to dispersion/detachment or dissolution of cells, which release from the biofilm and seed new surfaces with the consequent establishment of disseminated candidiasis at distal organs. Additionally, there are indications that dispersed cells from biofilms are more virulent than planktonic cells [86]. Negri et al. [84] detected that $C$. tropicalis cells are able to detach from biofilms formed in catheters under a flow of artificial urine and move upflow. However, little is still known about $C$. tropicalis detachment cells from biofilms and more studies are necessary to better understand this process.

Infection and dissemination

Adherence of $C$. tropicalis to host cells, and consequently colonization, is seen as an essential early step in the establishment of disease, since high density colonization is indicative of high risk factor to the host [61, 64]. It is known that $C$. tropicalis is able to adhere, colonize and infect host tissues and further disseminate, both in vivo and in vitro $[21,22,81,83]$.

It is interesting to observe that, according to some researchers, $C$. tropicalis strains showed intermediate levels of adherence to buccal epithelial cells [30, 83] and to human epithelial cell monolayers [94], whereas C. albicans strains showed high in vitro adherence. However, in other studies, C. tropicalis showed similar or higher extent of adhesion than $C$. albicans when in contact with human epithelial cell monolayers [95] and endothelium from porcine vascular tissues [96]. Therefore, it is possible to verify that Candida species do not adhere in the same manner to the different mucosal types of cells, and also that there is distinct interaction between epithelium morphology and molecular events during Candida adhesion [97].

In a recent in vivo experimental study in mice, Okawa et al. [98] observed that the pathogenicity of $C$. tropicalis strains was not correlated with the adherence ability. Silva et al. [81] recently demonstrated that only filamentous forms of C. tropicalis were able to invade an oral epithelium reconstituted model. In fact, hyphae have an important role in tissue invasion, and in vitro research has shown that $C$. albicans lacking hyphal formation exhibited lower ability for tissue invasion compared with wild-type $C$. albicans strains [99]. The morphological forms exhibited by $C$. tropicalis are similar to those shown by $C$. albicans, but despite these few studies, there is no more evidence on the importance of $C$. tropicalis morphology in virulence. Furthermore, these studies indicate that after prolonged infection $C$. tropicalis increases its infectivity, causing more tissue damage and mice mortality [21, 81, 99]. Corroborating this fact, $C$. tropicalis was found to be highly invasive after $12 \mathrm{~h}$ of infection, with extensive tissue damage occurring after $24 \mathrm{~h}$ [81].

Thus, the pathogenic mechanisms of $C$. tropicalis seem to be different from those of $C$. albicans [21, 95]. A significant work [100] on pathogenicity of Candida species in an animal model showed that the most pathogenic group was $C$. albicans and $C$. tropicalis, followed by an intermediate group with $C$. glabrata, $C$. lusitaniae and $C$. kefyr and a least pathogenic group of $C$. parapsilosis, $C$. 
Table 4 Candida tropicalis virulence factors analysed and major conclusions

\begin{tabular}{|c|c|c|}
\hline Reference & Virulence factor & Candida $\mathrm{sp} .(n)$ \\
\hline [96] & $\begin{array}{l}\text { Adhesion to biotic surface and } \\
\text { infection }\end{array}$ & $\begin{array}{l}\text { C. tropicalis (1); C. albicans (1); } \\
\text { C. parapsilosis (1); C. glabrata (1); } \\
\text { C. krusei (1); C. pseudotropicalis (1) }\end{array}$ \\
\hline [30] & Adhesion to a biotic surface & $\begin{array}{l}\text { C. glabrata (12); C. lusitaniae (1); } \\
\text { C. kefyr (1); C. krusei (2); C. } \\
\text { colliculosa (1); C. parapsilosis (2); } \\
\text { C. tropicalis (2); C. albicans (12); }\end{array}$ \\
\hline [21] & $\begin{array}{l}\text { Adhesion to a biotic surface; } \\
\text { dissemination in vivo: }\end{array}$ & C. tropicalis (5); C. albicans (1) \\
\hline
\end{tabular}
hydrophobicity; acidic conditions; sucrose assimilation

Infection to epithelium; enzyme expression
C. tropicalis (2); C. parapsilosis (2); C. glabrata (2)
[110] Haemolyse activity

[108] Ezymes production and biofilm; susceptibility testing
Comments

Candida interaction with endothelium using porcine whole blood vessel. C. albicans and C. tropicalis adhered in a higher extent followed by C. krusei, C. parapsilosis, C. pseudotropicalis, and C. glabrata

This work studied the adherence of different Candida strains isolated from the human gastrointestinal tract. Adherence to buccal epithelial cells was maximal for $C$. albicans, $C$. tropicalis and C. parapsilosis and minimal for C. krusei

C. tropicalis strains were tested for their lethality in mice, adherence to Hela cells, hydrophobicity, yeast growth under acidic conditions ( $\mathrm{pH} 2.0-5.9)$ and sucrose assimilation. The pathogenicity in mice by all the tested C. tropicalis strains was not correlated with the adherence, the hydrophobicity, or yeast growth. The pathogenicity correlated well with the sucrose assimilation ability. Pathogenic mechanisms of C. tropicalis strains were different from those of the C. albicans assayed

This study investigated the infectivity of C. tropicalis isolates using a reconstituted human oral epithelium (RHOE) and secreted aspartyl proteinase (SAPT) gene expression. SAPT1-4 genes expression was straindependent, with $S A P T 2-4$ transcripts being frequently detected and SAPTI rarely detected. C. tropicalis was highly invasive with the ability to induce significant tissue damage. These features, however, do not appear to be related to specific $S A P T$ gene expression

This work compared both the adhesion and biofilm formation on silicone of urinary clinical isolates in the presence of urine. NCAC species were able to adhere to and survive on silicone in the presence of urine. Similar water contact angle values were obtained for all NCAC strains. C. glabrata strains presented higher colonization abilities than C. tropicalis and C. parapsilosis strains

In this study, the chemical matrix composition of $C$. albicans and C. tropicalis biofilms and biofilm drug resistance were analysed. C. tropicalis biofilm matrix contained carbohydrates, proteins, hexosamine, phosphorus and uronic acid, but its major component was hexosamine, whereas in C. albicans matrix the major component was glucose. Biofilms of C. tropicalis synthesized large amounts of matrix material and such biofilms were completely resistant to both amphotericin B and fluconazole

This study investigated the characteristics of $C$. tropicalis biofilm development regarding the different growth phases, morphology and antifungal susceptibility. Mature biofilms consisted of a dense network of yeast cells and filamentous forms of C. tropicalis. Increased resistance of sessile cells against fluconazole and amphotericin B was detected. Sessile cells overexpressed ERG11 and MDR1 by realtime PCR, indicating fluconazole resistance by $C$. tropicalis biofilm

This is the first study demonstrating the variable expression profiles of haemolysins by different Candida species. Total and partial hemolysis was detectable in C. albicans, $C$. dubliniensis, C. kefyr, C. krusei, C. zeylanoides, C. glabrata, C. tropicalis, and C. lusitaniae. Only partialhemolysis was detectable in C. famata, C. guilliermondii, C. rugosa, and C. utilis. No hemolytic activity was observed in C. parapsilosis and C. pelliculosa

The production of acid protease, phospholipase, haemolysin, and biofilm formation was evaluated. One isolate of $C$. tropicalis had a strong positive phospholipase activity and high resistance to fluconazole. All isolates showed hemolytic activity 
Table 4 (continued)

\begin{tabular}{|c|c|c|c|}
\hline Reference & Virulence factor & Candida sp. (n) & Comments \\
\hline$[104]$ & Enzymes production & $\begin{array}{l}\text { C. tropicalis }(9) ; \text { C. albicans }(60) ; \\
\text { C. glabrata (4); C. parapsilosis (2); } \\
\text { C. lusitaniae (1); C. famata (3); } \\
\text { C. guilliermondii (3); C. rugosa (2); } \\
\text { C. kefyr (4); C. krusei (6); C. } \\
\text { lipolytica (4) }\end{array}$ & $\begin{array}{l}\text { Phospholipase and protease activities were tested in clinical } \\
\text { Candida isolates with reference to the sources of strains. } \\
\text { Protease producers in NCAC species were observed as } C \text {. } \\
\text { kefyr, } C \text {. lipolytica, } C \text {. parapsilosis and } C \text {. tropicalis. } \\
\text { Candida albicans isolates tested were phospholipase } \\
\text { producers and only a few strains of } C \text {. glabrata and } C \text {. kefyr } \\
\text { behaved in the same way. The quantity of phospholipase } \\
\text { produced by } C \text {. albicans varied with the specific isolate } \\
\text { and correlation with the site of infection }\end{array}$ \\
\hline$[107]$ & Enzymes production & C. tropicalis (19); C. albicans (77) & $\begin{array}{l}\text { Candida albicans and } C \text {. tropicalis were obtained from whole } \\
\text { saliva of patients presenting signs of oral candidosis. } \\
\text { Proteinase activity was observed in both } C \text {. albicans and } C \text {. } \\
\text { tropicalis, but phospholipase activity was only noted in } \\
\text { C. albicans. In vitro resistance to antifungals was verified in } \\
\text { both species, but } C \text {. tropicalis appears to be more resistant to } \\
\text { the tested antifungals than } C \text {. albicans }\end{array}$ \\
\hline$[113]$ & Enzymes production & $\begin{array}{l}\text { C. tropicalis }(11) ; \text { C. albicans }(24) ; \\
\text { C. glabrata }(22) ; \text { C. krusei }(5)\end{array}$ & $\begin{array}{l}\text { The aim was to determine the enzymatic activity and to } \\
\text { investigate the distribution of phospholipase C gene } \\
\text { of several Candida isolates from patients with pulmonary } \\
\text { tuberculosis and non tuberculosis patients. Phospholipase } \\
\text { activity from } C \text {. albicans, C. tropicalis and } C \text {. krusei } \\
\text { exhibited some similarity in both groups. Candida isolates } \\
\text { invariably showed high levels of phospholipase, proteinase, } \\
\text { caseinase and lipase activities }\end{array}$ \\
\hline$[22]$ & $\begin{array}{l}\text { Adhesion to abiotic surface and } \\
\text { biofilm formation; adhesion to } \\
\text { biotic surface; hyphae formation; } \\
\text { enzymes production; susceptibility } \\
\text { testing }\end{array}$ & C. tropicalis $(7)$ & $\begin{array}{l}\text { Characterization of } C \text {. tropicalis virulence and antifungal } \\
\text { susceptibility. All clinical isolates presented one or more } \\
\text { virulence factors. Candida tropicalis strains adhered } \\
\text { significantly more to epithelium than to silicone. All strains } \\
\text { were able to form biofilms and to express total haemolytic } \\
\text { activity. However, protease was only produced by two } \\
\text { isolates. Only one strain was phospholipase positive. Four } \\
\text { strains were susceptible-dose dependent to itraconazole and } \\
\text { one clinical isolate was found to be resistant. It was not } \\
\text { possible to establish a relation among the virulence factors } \\
\text { assayed }\end{array}$ \\
\hline
\end{tabular}

krusei and C. guillerimondii. It is important to emphasize the clinical relevance of those findings, since the major problems with the development of invasive $C$. tropicalis candidosis are associated with high dissemination and mortality.

\section{Enzymes production}

Once adhered to host cells, C. tropicalis requires other factors to penetrate into the deepest tissues, e.g., hyphal formation and production of enzymes. In fact, the pathogenic capabilities of this yeast have been related to the secretion of aspartyl proteinases, phospholipases and haemolytic activity $[22,24,25,65,79,101]$.

Candida produce a large variety of secreted hydrolases, and among the various potential virulence factors proposed, the secreted aspartyl proteinases (Sap) have been intensively investigated. It is now well established that the ability of C. albicans to adhere to mucosae, to invade in deep organs, and to resist to phagocytic cells, apparently requires the use of several different proteinases suitable to each particular condition during the infection. Like $C$. albicans, $C$. tropicalis presents in vitro Sap activity in a medium containing bovine serum albumin (BSA) as the sole source of nitrogen [22, 31, 79, 102].

Furthermore, Zaugg et al. [24] characterized a total of four $S A P T$ gene families of $C$. tropicalis. According to this study, RT-PCR experiments revealed a strong SAPT1 signal with RNA extracted from cells grown in BSA medium. The SAPT2 and SAPT3 gene products, Sapt2p and Sapt $3 p$, which have not yet been detected in C. tropicalis cultures in vitro, were produced as active recombinant enzymes with the methylotrophic yeast Pichia pastoris as an expression system. However, a weak signal was obtained with all other $S A P T$ genes under in vitro conditions tested, suggesting that the gene products Sapt $2 p$, Sapt $3 p$, and Sapt $4 p$ could be produced during infection.

This idea is highlighted by recent studies [81, 99] that investigated epithelial infection by $C$. tropicalis using a reconstituted human oral epithelium (RHOE) and SAPT gene expression. The results obtained by real-time PCR showed that $C$. tropicalis isolates were able to express 
SAPT1-4 during the infection process. Moreover, expression was strain-dependent, with $S A P T 2-4$ transcripts being frequently detected and SAPT1 rarely detected. Furthermore, $C$. tropicalis can be considered as highly invasive with the ability to induce significant tissue damage [81]. These features, however, do not appear to be related to specific $S A P T$ gene expression. Therefore it is necessary to perform more investigations focusing on SAPT gene families of $C$. tropicalis for better understanding the specific role of these genes.

In addition to Saps, enzymes categorized as lipases (LIPs), i.e., enzymes that hydrolyze phospholipids into fatty acids, are often considered to be involved in $C$. tropicalis pathogenicity and are suggested to contribute to host cell membrane damage which could also expose receptors to facilitate adherence $[101,103,104]$. In $C$. albicans, ten genes encoding for LIPs (LIP1-10) have been identified and similar sequences were also detected in C. tropicalis [105]. Nevertheless, the most widely used diagnostic method for phospholipases (PLs) determination is based on yeast growth in an egg yolk agar medium [106]. According to recent studies, using this method, $C$. tropicalis, from different sources, appears to have a reduced ability to produce extracellular PLs in vitro when compared to $C$. albicans $[29,104,107]$. However, this production is highly species and strain dependent $[22,25$, 108, 109].

Other important virulence factor recently described in literature is related with haemolytic activity which is tested on sheep blood agar supplemented with glucose [110]. It is known that enzymes as haemolysins are used by Candida species to degrade haemoglobin and facilitate recovery of the elemental iron from host cells, which is a contribution to pathogenicity in Candida species. Thus, haemolysins are considered key virulence factors enabling pathogen survival and persistence in the host [110-112]. The studies reported so far show that $C$. tropicalis are all able to produce haemolysins in vitro, inducing partial or total erythrocyte lyses, although the degree is strain dependent [110]. According to Luo et al. [110], total-haemolytic activities in C. albicans and $C$. tropicalis were significantly higher than in C. glabrata. However, Kumar et al. [113] observed the opposite, $C$. glabrata displayed the highest haemolytic activity when compared with $C$. albicans and C. tropicalis. Although significant studies showed the ability of $C$. tropicalis to produce haemolytic activity on sheep blood agar supplemented with glucose, it is important to assess whether the haemolytic activity observed is true or is a product of extracellular PLs of Candida species. Moreover, it is still necessary to have more advances in molecular studies to clarify the role of haemolytic activity in C. tropicalis pathogenesis.
Concluding remarks

In fact, the frequency of Candida tropicalis causing candidosis has been increasing in recent decades, probably due to several situations, e.g., new and efficient molecular methods of identification; antifungal resistance, mainly to fluconazole commonly used as prophylaxis agent; and factors related with host as well as invasiveness surgery, long periods in ICU, antibiotic administration and catheterization. Additionally, invasive disease developed by $C$. tropicalis is associated with colonization, high potential of dissemination and pathogenicity by this organism. This is mainly because $C$. tropicalis possesses a diversity of virulence factors that induce serious damage to patients and increases the mortality risk. However, much more research is necessary to get deeper insights into the strategies used by $C$. tropicalis to change from a harmless commensal microorganism to become a human pathogen of high clinical concern.

Acknowledgments The authors acknowledge Coordenação de Aperfeiçoamento de Pessoal de Nível Superior (CAPES), Brazil, for supporting Melyssa Negri (BEX 4642/06-6) and Fundação para a Ciência e Tecnologia (FCT), Portugal, for supporting Sonia Silva (SFRH/BPD/71076/2010), and European Community fund FEDER, trough Program COMPETE under the Project FCOMP-01-0124-FEDER-007025 (PTDC/AMB/68393/2006) is gratefully acknowledged.

Conflicts of interest None declared.

\section{References}

1. Hota B (2004) Contamination, disinfection, and cross colonization: are hospital surfaces reservoirs for nosocomial infection? Clin Infect Dis 39(8):1182-1189. doi:10.1086/424667

2. Gudlaugsson O, Gillespie S, Lee K, Vande Berg J, Hu J, Messer S, Herwaldt L, Pfaller M, Diekema D (2003) Attributable mortality of nosocomial candidemia, revisited. Clin Infect Dis 37(9):1172-1177. doi:10.1086/378745

3. Bassetti M, Righi E, Costa A, Fasce R, Molinari M, Rosso R, Pallavicini F, Viscoli C (2006) Epidemiological trends in nosocomial candidemia in intensive care. BMC Infect Dis 6 (1):21. doi:10.1186/1471-2334-6-21

4. Cheng M-F, Yang Y-L, Yao T-J, Lin C-Y, Liu J-S, Tang R-B, Yu KW, Fan Y-H, Hsieh K-S, Ho M, Lo H-J (2005) Risk factors for fatal candidemia caused by Candida albicans and non-albicans Candi$d a$ species. BMC Infect Dis 5(1):22. doi:10.1186/1471-2334-5-22

5. Dimopoulos G, Ntziora F, Rachiotis G, Armaganidis A, Falagas ME (2008) Candida albicans versus non-albicans intensive care unit-acquired bloodstream infections: differences in risk factors and outcome. Anesth Analg 106(2):523-529. doi:10.1213/ ane.0b013e3181607262

6. Meric M, Willke A, Caglayan C, Toker K (2005) Intensive care unit-acquired infections: incidence, risk factors and associated mortality in a Turkish university hospital. Jpn J Infect Dis 58 (5):297-302 
7. Lass-Flörl C (2009) The changing face of epidemiology of invasive fungal disease in Europe. Mycoses 52(3):197-205. doi:10.1111/j.1439-0507.2009.01691.x

8. Eggimann P, Garbino J, Pittet D (2003) Epidemiology of Candida species infections in critically ill nonimmunosuppressed patients. Lancet Infect Dis 3(11):685-702. doi:10.j.clp.2007.1/S1473-3099(03)00801-6

9. Snydman DR (2003) Shifting patterns in the epidemiology of nosocomial Candida infections. Chest 123(5 Suppl):500S-503S. doi:10.1378/chest.123.5 suppl.500S

10. Lundstrom T, Sobel J (2001) Nosocomial Candiduria: a review. Clin Infect Dis 32(11):1602-1607. doi:10.1086/320531

11. Krcmery V, Barnes AJ (2002) Non-albicans Candida spp. causing fungaemia: pathogenicity and antifungal resistance. $\mathrm{J}$ Hosp Infect 50(4):243-260. doi:10.1053/jhin.2001.1151

12. Colombo AL, Nucci M, Park BJ, Nouer SA, Arthington-Skaggs B, da Matta DA, Warnock D, Morgan J, for the Brazilian Network Candidemia S (2006) Epidemiology of Candidemia in Brazil: a nationwide sentinel surveillance of Candidemia in eleven medical centers. J Clin Microbiol 44(8):2816-2823. doi:10.1128/jcm.00773-06

13. Chakrabarti A, Chatterjee SS, Rao KLN, Zameer MM, Shivaprakash MR, Singhi S, Singh R, Varma SC (2009) Recent experience with fungaemia: change in species distribution and azole resistance. Scand J Infect Dis 41(4):275-284. doi:10.1080/ 00365540902777105

14. Tortorano AM, Peman J, Bernhardt H, Klingspor L, Kibbler CC, Faure O, Biraghi E, Canton E, Zimmermann K, Seaton S, Grillot R, the EWGoC (2004) Epidemiology of Candidaemia in Europe: results of 28-Month European Confederation of Medical Mycology (ECMM) hospital-based surveillance study. Eur J Clin Microbiol Infect Dis 23(4):317-322. doi:10.1007/s10096-004-1103-y

15. Nucci M, Colombo AL (2007) Candidemia due to Candida tropicalis: clinical, epidemiologic, and microbiologic characteristics of 188 episodes occurring in tertiary care hospitals. Diagn Microbiol Infect Dis 58(1):77-82. doi:10.j.clp.2007.1/j.diagmi crobio.2006.11.009

16. Hsueh P-R, Graybill JR, Playford EG, Watcharananan SP, Oh MD, Já alam K, Huang S, Nangia V, Kurup A, Padiglione AA (2009) Consensus statement on the management of invasive candidiasis in intensive care units in the Asia-Pacific Region. Int J Antimicro Ag 34(3):205-209. doi:10.j.clp.2007.1/j.ijantimi cag.2009.03.014, 34

17. Álvarez-Lerma F, Nolla-Salas J, León C, Palomar M, Jordá R, Carrasco N, Bobillo F (2003) Candiduria in critically ill patients admitted to intensive care medical units. Intensive Care Med 29 (7):1069-1076. doi:10.1007/s00134-003-1807-y

18. Kauffman CA, Vazquez JA, Sobel JD, Gallis HA, McKinsey DS, Karchmer AW, Sugar AM, Sharkey PK, Wise GJ, Mangi R, Mosher A, Lee JY, Dismukes WE (2000) Prospective multicenter surveillance study of funguria in hospitalized patients. Clin Infect Dis 30(1):14-18. doi:10.1086/313583

19. Krcmery VJ (1999) Candidemia in cancer patients: Risk factors and outcome in 140 episodes from a single cancer institution. Acta Chemoth 5:133-145

20. Kontoyiannis Dimitrios P, Vaziri I, Hanna Hend A, Boktour M, Thornby J, Hachem R, Bodey Gerald P, Raad Issam I (2001) Risk factors for Candida tropicalis fungemia in patients with cancer. Clin Infect Dis 33(10):1676-1681. doi:10.1086/323812

21. Okawa Y, Miyauchi M, Kobayashi H (2008) Comparison of pathogenicity of various Candida tropicalis strains. Biol Pharm Bull 31(8):1507-1510. doi:10.1248/bpb.31.1507

22. Negri M, Martins M, Henriques M, Svidzinski T, Azeredo J, Oliveira R (2010) Examination of potential virulence factors of Candida tropicalis clinical isolates from hospitalized patients. Mycopathologia 169(3):175-182. doi:10.1007/s11046-009-9246-0
23. Bizerra FC, Nakamura CV, de Poersch C, Svidzinski TIE, Quesada RMB, Goldenberg S, Krieger MA, Yamada-Ogatta SF (2008) Characteristics of biofilm formation by Candida tropicalis and antifungal resistance. FEMS Yeast Res 8(3):442-450. doi:10.1111/j.1567-1364.2007.00347.x

24. Zaugg C, Borg-von Zepelin M, Reichard U, Sanglard D, Monod M (2001) Secreted aspartic proteinase family of Candida tropicalis. Infect Immun 69(1):405-412. doi:10.1128/iai.69.1.405-412.2001

25. Galan-Ladero MA, Blanco MT, Sacristan B, FernandezCalderan MC, Perez-Giraldo C, Gomez-Garcia AC (2010) Enzymatic activities of Candida tropicalis isolated from hospitalized patients. Med Mycol 48(1):207-210. doi:10.1080/13693780902801242

26. Larone D (2002) Medically important fungi; a guide to identification, 4th edn. ASM Press, Washington

27. Kurtzman CP, Fell JW (1998) The yeasts, a taxonomic study, 4th edn. Elsevier Science Ltd, New York

28. Basu S, Gugnani H, Joshi S, Gupta N (2003) Distribution of Candida species in different clinical sources in Delhi, India, and proteinase and phospholipase activity of Candida albicans isolates. Rev Iberoam Micol 20(4):137-140

29. Oksuz S, Sahin I, Yildirim M, Gulcan A, Yavuz T, Kaya D, Koc A (2007) Phospholipase and proteinase activities in different Candida species isolated from anatomically distinct sites of healthy adults. Jpn J Infect Dis 60(5):280-283

30. Biasoli MS, Tosello ME, Bottai H, Cuesta C, Magaró HM (2002) Adherence of Candida strains isolated from the human gastrointestinal tract. Mycoses 45(11-12):465-469. doi:10.1046/ j.1439-0507.2002.00793.x

31. Tamura NK, Negri MFN, Bonassoli LA, Svidzinski TIE (2007) Fatores de virulência de Candida spp isoladas de cateteres venosos e mãos de servidores hospitalares. Rev Soc Bras Med Trop 40(1):91-93. doi:10.1590/S0037-86822007000100021

32. Shurtleff DB, Peterson W, Sherris JC (1963) Systemic Candida tropicalis infection treated with amphotericin. N Engl J Med 269:1112-1115. doi:10.1056/NEJM196311212692102

33. HO D (1960) The pathogenicity of Candida tropicalis. Can Med Assoc J 83(27):1439-1440

34. Nucci M, Silveira M, Spector N, Silveira F, Velasco E, Martins C, Derossi A, Colombo A, Pulcheri W (1998) Fungemia in cancer patients in Brazil: Predominance of non-albicans species. Mycopathologia 141(2):65-68. doi:10.1023/A:1006951619245

35. Rho J, Shin J, Song J, Park M, Kee S, Jang S, Park Y, Suh S, Ryang D (2004) Molecular investigation of two consecutive nosocomial clusters of Candida tropicalis candiduria using pulsed-field gel electrophoresis. J Microbiol 42(2):80-86

36. Kliemann DA, Pasqualotto AC, Falavigna M, Giaretta T, Severo LC (2008) Candida esophagitis: species distribution and risk factors for infection. Rev Inst Med Trop Sao Paulo 50:261-263. doi:10.1590/S0036-46652008000500002

37. Silva EHd, Ruiz LdS, Matsumoto FE, Auler ME, Giudice MC, Moreira D, Szeszs W, Paula CR (2007) Candiduria in a public hospital of São Paulo (1999-2004): characteristics of the yeast isolates. Rev Inst Med Trop Sao Paulo 49(6):349-353. doi:10.1590/S0036-46652007000600003

38. Silva EH, Ruiz LS, Matsumoto FE, Auler ME, Giudice MC, Moreira D, Szeszs W, Paula CR (2007) Candiduria in a public hospital of São Paulo (1999-2004): characteristics of the yeast isolates. Rev Inst Med Trop Sao Paulo 49(6):349-353. doi:10.1590/S0036-46652007000600003

39. Calderone RA (2002) Introduction and historical perspectives. In: Calderone R (ed) Candida and candidiasis. ASM Press, Washington D.C., pp 15-25

40. Yoshio O, Kouji G (2006) Antigenicity of Candida tropicalis strain cells cultured at 27 and $37^{\circ} \mathrm{C}$. FEMS Immunol Med Microbiol 46(3):438-443 
41. Martin MV (1979) Germ-tube formation by oral strains of Candida tropicalis. J Med Microbiol 12(2):187-194. doi:10.1099/ 00222615-12-2-187

42. Butler G, Rasmussen MD, Lin MF, Santos MAS, Sakthikumar S, Munro CA, Rheinbay E, Grabherr M, Forche A, Reedy JL, Agrafioti I, Arnaud MB, Bates S, Brown AJP, Brunke S, Costanzo MC, Fitzpatrick DA, de Groot PWJ, Harris D, Hoyer LL, Hube B, Klis FM, Kodira C, Lennard N, Logue ME, Martin R, Neiman AM, Nikolaou E, Quail MA, Quinn J, Santos MC, Schmitzberger FF, Sherlock G, Shah P, Silverstein KAT, Skrzypek MS, Soll D, Staggs R, Stansfield I, Stumpf MPH, Sudbery PE, Srikantha T, Zeng Q, Berman J, Berriman M, Heitman J, Gow NAR, Lorenz MC, Birren BW, Kellis M, Cuomo CA (2009) Evolution of pathogenicity and sexual reproduction in eight Candida genomes. Nature 459(7247):657-662. doi:10.1038/nature08064

43. Bennett RJ (2009) A Candida-based view of fungal sex and pathogenesis. Genome Biol 10(7):230. doi:10.1186/gb-200910-7-230

44. Zhang J, Hollis RJ, Pfaller MA (1997) Variations in DNA subtype and antifungal susceptibility among clinical isolates of Candida tropicalis. Diagn Microbiol Infect Dis 27(3):63-67

45. Fricke S, Fricke C, Schimmelpfennig C, Oelkrug C, Schönfelder U, Blatz R, Zilch C, Faber S, Hilger N, Ruhnke M, Rodloff AC (2010) A real-time PCR assay for the differentiation of Candida species. J Appl Microbiol 109(4):1150-1158. doi:10.1111/ j.1365-2672.2010.04736.x

46. Williams DW, Wilson MJ, Lewis MA, Potts AJ (1995) Identification of Candida species by PCR and restriction fragment length polymorphism analysis of intergenic spacer regions of ribosomal DNA. J Clin Microbiol 33(9):2476-2479

47. Kanbe T, Horii T, Arishima T, Ozeki M, Kikuchi A (2002) PCRbased identification of pathogenic Candida species using primer mixes specific to Candida DNA topoisomerase II genes. Yeast 19(11):973-989. doi:10.1002/yea.892

48. Schabereiter-Gurtner C, Selitsch B, Rotter ML, Hirschl AM, Willinger B (2007) Development of novel real-time PCR assays for detection and differentiation of eleven medically important Aspergillus and Candida species in clinical specimens. J Clin Microbiol 45(3):906-914. doi:10.1128/JCM.01344-06

49. Quiles-Melero I, Garcia-Rodriguez J, Romero-Gomez MP, Gomez-Sanchez P, Mingorance J (2010) Rapid identification of yeasts from positive blood culture bottles by pyrosequencing. Eur J Clin Microbiol Infect Dis. doi:10.1007/s10096-010-1045-5

50. Liguori G, Lucariello A, Colella G, De Luca A, Marinelli P (2007) Rapid identification of Candida species in oral rinse solutions by PCR. J Clin Pathol 60(9):1035-1039. doi:10.1136/ jcp.2006.040782

51. Bustamante CI (2005) Treatment of Candida infection: a view from the trenches! Curr Opin Infect Dis 18(6):490-495

52. Bougnoux ME, Kac G, Aegerter P, Fagon JY, d'Enfert C (2008) Candidemia and candiduria in critically ill patients admitted to intensive care units in France: incidence, molecular diversity, management and outcome. Intensive Care Med 34(2):292-299. doi:10.1007/s00134-007-0865-y

53. Carey AJ, Saiman L, Polin RA (2008) Hospital-acquired infections in the NICU: epidemiology for the new millennium. Clin Perinatol 35(1):223-249. doi:10.j.clp.2007.1/j.clp.2007.11.014

54. Shorr AF, Tabak YP, Johannes RS, Sun X, Spalding J, Kollef MH (2009) Candidemia on presentation to the hospital: development and validation of a risk score. Crit Care 13(5):R156. doi:10.1186/cc8110

55. Cisterna R, Ezpeleta G, Telleria O, Guinea J, Regueiro B, Garcia-Rodriguez J, Esperalba J (2010) Nationwide sentinel surveillance of bloodstream Candida infections in 40 tertiary care hospitals in Spain. J Clin Microbiol 48(11):4200-4206. doi:10.1128/JCM.00920-10
56. Nucci M, Queiroz-Telles F, Tobon AM, Restrepo A, Colombo AL (2010) Epidemiology of opportunistic fungal infections in Latin America. Clin Infect Dis 51(5):561-570. doi:10.1086/655683

57. Kojic EM, Darouiche RO (2004) Candida infections of medical devices. Clin Microbiol Rev 17(2):255-267. doi:10.1128/ cmr.17.2.255-267.2004

58. Achkar JM, Fries BC (2010) Candida infections of the genitourinary tract. Clin Microbiol Rev 23(2):253-273. doi:10.1128/CMR.00076-09

59. Jain N, Kohli R, Cook E, Gialanella P, Chang T, Fries BC (2007) Biofilm formation by and antifungal susceptibility of Candida isolates from urine. Appl Environ Microbiol 73(6):1697-1703. doi:10.1128/aem.02439-06

60. Pfaller MA (1992) Laboratory aids in the diagnosis of invasive candidiasis. Mycopathologia 120(2):65-72

61. Viale P (2009) Candida colonization and candiduria in critically ill patients in the intensive care unit. Drugs 69:51-57. doi:10.2165/11315640-000000000-00000

62. Paul N, Mathai E, Abraham OC, Michael JS, Mathai D (2007) Factors associated with candiduria and related mortality. J Infect 55(5):450-455. doi:10.j.clp.2007.1/j.jinf.2007.06.010

63. Binelli CA, Moretti ML, Assis RS, Sauaia N, Menezes PR, Ribeiro E, Geiger DC, Mikami Y, Miyaji M, Oliveira MS, Barone AA, Levin AS (2006) Investigation of the possible association between nosocomial candiduria and candidaemia. Clin Microbiol Infect 12(6):538-543. doi:10.1111/j.14690691.2006.01435.x

64. Munoz P, Giannella M, Fanciulli C, Guinea J, Valerio M, Rojas L, Rodriguez-Creixems M, Bouza E (2010) Candida tropicalis fungaemia: incidence, risk factors and mortality in a general hospital. Clin Microbiol Infect. doi:10.1111/j.14690691.2010.03338.x

65. Kothavade RJ, Kura MM, Valand AG, Panthaki MH (2010) Candida tropicalis: its prevalence, pathogenicity and increasing resistance to fluconazole. J Med Microbiol 59(Pt 8):873-880. doi:10.1099/jmm.0.013227-0

66. Colombo AL, Guimarães T, Silva LRBF, Monfardini LPA, Cunha AKB, Rady P, Alves T, Rosas RC (2007) Prospective observational study of candidemia in São Paulo, Brazil: Incidence rate, epidemiology, and predictors of mortality. Infect Control Hosp Epidemiol 28(5):570-576. doi:10.1086/513615

67. Falagas ME, Roussos N, Vardakas KZ (2010) Relative frequency of albicans and the various non-albicans Candida spp among candidemia isolates from inpatients in various parts of the world: a systematic review. Int J Infect Dis 14(11):954-966. doi:10.j. clp.2007.1/j.ijid.2010.04.006

68. Paulo C, Mourão C, Veiga PM, Marques JM, Rocha G, Alves AF, Querol A, Meliço-Silvestre AA, Gonçalves I, Flores O, Clemente C, Gonçalves T (2009) Retrospective analysis of clinical yeast isolates in a hospital in the centre of Portugal: spectrum and revision of the identification procedures. Med Mycol 19(1):1-10. doi:10.1080/13693780802709081

69. Pfaller MA, Diekema DJ (2007) Epidemiology of invasive Candidiasis: a persistent public health problem. Clin Microbiol Rev 20(1):133-163. doi:10.1128/cmr.00029-06

70. Chen K, Chen Y, Lin Y, Chou H, Li S (2009) The molecular epidemiology of serial Candida tropicalis isolates from ICU patients as revealed by multilocus sequence typing and pulsedfield gel electrophoresis. Infect Genet Evol 9(5):912-920. doi:10.j.clp.2007.1/j.meegid.2009.06.011

71. Pappas Peter G, Kauffman Carol A, Andes D, Benjamin J, Daniel K, Calandra Thierry F, Edwards John E, Filler Scott G, Fisher John F, Kullberg BJ, Ostrosky-Zeichner L, Reboli AC, Rex John H, Walsh Thomas J, Sobel Jack D (2009) Clinical practice guidelines for the management of Candidiasis: 2009 
update by the infectious diseases society of America. Clin Infect Dis 48(5):503-535. doi:10.1086/596757

72. Pfaller MA, Boyken L, Hollis RJ, Kroeger J, Messer SA, Tendolkar S, Diekema DJ (2009) Comparison of results of fluconazole and voriconazole disk diffusion testing for Candida spp. with results from a central reference laboratory in the ARTEMIS DISK Global Antifungal Surveillance Program. Diagn Microbiol Infect Dis 65(1):27-34. doi:10.j.clp.2007.1/j. diagmicrobio.2009.05.007

73. Negri M, Henriques M, Svidzinski TIE, Paula CR, Oliveira R (2009) Correlation between Etest ${ }^{\mathbb{R}}$, disk diffusion, and microdilution methods for antifungal susceptibility testing of Candida species from infection and colonization. J Clin Lab Anal 23 (5):324-330. doi:10.1002/jcla.20337

74. Desnos-Ollivier M, Bretagne S, Bernede C, Robert V, Raoux D, Chachaty E, Forget E, Lacroix C, Dromer F (2008) Clonal population of flucytosine-resistant Candida tropicalis from blood cultures, Paris, France. Emerg Infect Dis 14(4):557-565

75. Bedini A, Venturelli C, Mussini C, Guaraldi G, Codeluppi M, Borghi V, Rumpianesi F, Barchiesi F, Esposito R (2006) Epidemiology of candidaemia and antifungal susceptibility patterns in an Italian tertiary-care hospital. Clin Microbiol Infect 12(1):75-80. doi:10.1111/j.1469-0691.2005.01310.x

76. Krcmery V (1999) Torulopsis glabrata an emerging yeast pathogen in cancer patients. Int J Antimicrob Agents 11(1):1-6

77. Kumar C, Kumar S, Menon T (2006) Phospholipase and proteinase activities of clinical isolates of Candida from immunocompromised patients. Mycopathologia 161(4):213218. doi:10.1007/s11046-005-0157-4

78. Hoyer LL, Fundyga R, Hecht JE, Kapteyn JC, Klis FM, Arnold J (2001) Characterization of agglutinin-like sequence genes from non-albicans Candida and phylogenetic analysis of the ALS family. Genetics 157(4):1555-1567

79. Yang Y (2003) Virulence factors of Candida species. J Microbiol Immunol Infect 36(4):223-228

80. Silva S, Negri $M$, Henriques $M$, Oliveira R, Williams D, Azeredo J (2010) Silicone colonization by non-Candida albicans Candida species in the presence of urine. J Med Microbiol 59(Pt 7):747-754. doi:10.1099/jmm.0.017517-0

81. Silva S, Hooper SJ, Henriques M, Oliveira R, Azeredo J, Williams DW (2011) The role of secreted aspartyl proteinases in Candida tropicalis invasion and damage of oral mucosa. Clin Microbiol Infect 17(2):264-272. doi:10.1111/j.1469-0691.2010.03248.x

82. Silva S, Negri M, Henriques M, Oliveira R, Williams DW, Azeredo J (2011) Adherence and biofilm formation of nonCandida albicans Candida species. Trends Microbiol 19(5):241247. doi:10.j.clp.2007.1/j.tim.2011.02.003

83. Biasoli MS, Tosello ME, Luque AG, Magaró HM (2010) Adherence, colonization and dissemination of Candida dubliniensis and other Candida species. Med Mycol 48(2):291-297. doi:10.1080/13693780903114942

84. Negri M, Silva S, Henriques M, Azeredo J, Svidzinski T, Oliveira R (2011) Candida tropicalis biofilms: artificial urine, urinary catheters and flow model. Med Mycol 49(7):739-747

85. Hasan F, Xess I, Wang X, Jain N, Fries BC (2009) Biofilm formation in clinical Candida isolates and its association with virulence. Microbes Infect 11(8-9):753-761. doi:10.j.clp.2007.1/ j.micinf.2009.04.018

86. Blankenship JR, Mitchell AP (2006) How to build a biofilm: a fungal perspective. Curr Opin Microbiol 9(6):588-594. doi:10.j. clp.2007.1/j.mib.2006.10.003

87. Kumamoto CA (2002) Candida biofilms. Curr Opin Microbiol 5 (6):608-611. doi:10.j.clp.2007.1/S1369-5274(02)00371-5

88. Douglas LJ (2003) Candida biofilms and their role in infection. Trends Microbiol 11(1):30-36. doi:10.j.clp.2007.1/S0966-842X (02)00002-1
89. Al-Fattani MA, Douglas LJ (2006) Biofilm matrix of Candida albicans and Candida tropicalis: chemical composition and role in drug resistance. J Med Microbiol 55(8):999-1008. doi:10.1099/jmm.0.46569-0

90. Silva S, Henriques M, Martins A, Oliveira R, Williams D, Azeredo J (2009) Biofilms of non-Candida albicans Candida species: quantification, structure and matrix composition. Med Mycol 47(7):681-689. doi:10.1080/13693780802549594

91. Al-Dhaheri RS, Douglas LJ (2008) Absence of amphotericin Btolerant persister cells in biofilms of some Candida species. Antimicrob Agents Chemother 52(5):1884-1887. doi:10.1128/ aac. 01473-07

92. Loeffler J, Hagmeyer L, Hebart H, Henke N, Schumacher U, Einsele H (2000) Rapid detection of point mutations by fluorescence resonance energy transfer and probe melting curves in Candida species. Clin Chem 46(5):631-635

93. Gotz F (2002) Staphylococcus and biofilms. Mol Microbiol 43 (6): 1367-1378

94. Bendel CM (2003) Colonization and epithelial adhesion in the pathogenesis of neonatal candidiasis. Semin Perinatol 27(5):357364. doi:10.j.clp.2007.1/S0146-0005(03)00059-4

95. Bendel C, Hostetter M (1993) Distinct mechanisms of epithelial adhesion for Candida albicans and Candida tropicalis. Identification of the participating ligands and development of inhibitory peptides. J Clin Invest 92:1840-1849. doi:10.1172/JCI116775

96. Klotz SA, Drutz DJ, Harrison JL, Huppert M (1983) Adherence and penetration of vascular endothelium by Candida yeasts. Infect Immun 42(1):374-384

97. Sohn K, Senyürek I, Fertey J, Königsdorfer A, Joffroy C, Hauser N, Zelt G, Brunner H, Rupp S (2006) An in vitro assay to study the transcriptional response during adherence of Candida albicans to different human epithelia. FEMS Yeast Res 6 (7):1085-1093. doi:10.1111/j.1567-1364.2006.00130.x

98. Miyauchi M, Giummelly P, Yazawa S, Okawa Y (2007) Adhesion of Candida albicans to HeLa cells: studies using polystyrene beads. Biol Pharm Bull 30(3):588-590. doi:10.1248/bpb.30.588

99. Jayatilake J, Samaranayake Y, Cheung L, Samaranayake L (2006) Quantitative evaluation of tissue invasion by wild type, hyphal and SAP mutants of Candida albicans, and non-albicans Candida species in reconstituted human oral epithelium. J Oral Pathol Med 35(8):484-491. doi:10.1111/j.1600-0714.2006.00435.x

100. Arendrup M, Horn T, Frimodt-Moller N (2002) In vivo pathogenicity of eight medically relevant Candida species in an animal model. Infection 30(5):286-291. doi:10.1007/s15010002-2131-0

101. Ghannoum MA (2000) Potential role of phospholipases in virulence and fungal pathogenesis. Clin Microbiol Rev 13 (1):122-143. doi: $10.1128 / \mathrm{cmr} .13 .1 .122-143.2000$

102. Naglik JR, Challacombe SJ, Hube B (2003) Candida albicans secreted aspartyl proteinases in virulence and pathogenesis. Microbiol Mol Biol Rev 67(3):400-428. doi:10.1128/ mmbr.67.3.400-428.2003

103. Prakobphol A, Leffler H, Fisher SJ (1994) Specific adherence of Candida tropicalis to lysophospholipids. Biochemistry 33 (32):9496-9503

104. Kantarciôlu AS, Yücel A (2002) Phospholipase and protease activities in clinical Candida isolates with reference to the sources of strains. Mycoses 45(5-6):160-165. doi:10.1046/ j.1439-0507.2002.00727.x

105. Fu Y, Ibrahim AS, Fonzi W, Zhou X, Ramos CF, Ghannoum MA (1997) Cloning and characterization of a gene (LIP1) which encodes a lipase from the pathogenic yeast Candida albicans. Microbiology 143(Pt 2):331-340

106. Price M, Wilkinson I, Gentry L (1982) Plate method for detection of phospholipase activity in Candida albicans. Sabouraudia 20:714 
107. da Costa K, Ferreira J, Komesu M, Candido R (2009) Candida albicans and Candida tropicalis in oral candidosis: quantitative analysis, exoenzyme activity, and antifungal drug sensitivity. Mycopathologia 167(2):73-79. doi:10.1007/s11046-008-9154-8

108. Furlaneto-Maia L, Specian A, Bizerra F, de Oliveira M, Furlaneto M (2007) In vitro evaluation of putative virulence attributes of oral isolates of Candida spp. obtained from elderly healthy individuals. Mycopathologia 166(4):209-217. doi:10.1007/ s11046-008-9139-7

109. Cafarchia C, Romito D, Coccioli C, Camarda A, Otranto D (2008) Phospholipase activity of yeasts from wild birds and possible implications for human disease. Med Mycol 46(5):429434. doi:10.1080/13693780701885636

110. Luo G, Samaranayake LP, Yau JYY (2001) Candida species exhibit differential in vitro hemolytic activities. J Clin Microbiol 39(8):2971-2974. doi:10.1128/jcm.39.8.2971-2974.2001

111. Watanabe T, Takano M, Murakami M, Tanaka H, Matsuhisa A, Nakao N, Mikami T, Suzuki M, Matsumoto T (1999) Characterization of a haemolytic factor from Candida albicans. Microbiology 145(3):689-694. doi:10.1099/13500872-145-3-689

112. Manns JM, Mosser DM, Buckley HR (1994) Production of a hemolytic factor by Candida albicans. Infect Immun 62(11):5154-5156

113. Kumar VG, Latha R, Vedhagiri K, Sathiamoorthi T, Jayarani G, Sasikala R, Selvin J, Natarajaseenivasan K (2009) Phospholipase
$\mathrm{C}$, proteinase and hemolytic activities of Candida spp. isolated from pulmonary tuberculosis patients. J Mycol Med 19(1):3-10. doi:10.j.clp.2007.1/j.mycmed.2008.11.002

114. Chang HC, Leaw SN, Huang AH, Wu TL, Chang TC (2001) Rapid identification of yeasts in positive blood cultures by a multiplex PCR method. J Clin Microbiol 39(10):3466-3471. doi:10.1128/JCM.39.10.3466-3471.2001

115. Mokaddas EM, Al-Sweih NA, Khan ZU (2007) Species distribution and antifungal susceptibility of Candida bloodstream isolates in Kuwait: a 10-year study. J Med Microbiol 56 (2):255-259. doi:10.1099/jmm.0.46817-0

116. Tortorano AM, Kibbler C, Peman J, Bernhardt H, Klingspor L, Grillot R (2006) Candidaemia in Europe: epidemiology and resistance. Int J Antimicrob Agents 27(5):359-366. doi:10.j. clp.2007.1/j.ijantimicag.2006.01.002

117. Pfaller MA, Castanheira M, Messer SA, Moet GJ, Jones RN (2010) Variation in Candida spp. distribution and antifungal resistance rates among bloodstream infection isolates by patient age: report from the SENTRY Antimicrobial Surveillance Program (2008-2009). Diagn Microbiol Infect Dis 68(3):278283. doi:10.j.clp.2007.1/j.diagmicrobio.2010.06.015

118. Dorko E, Pilipčinec E, Tkáčiková L (2002) Candidal urinary tract infections caused by non-albicans Candida species. Folia Microbiol 47(2):182-184. doi:10.1007/BF02817679 